\title{
Polysilane Organogel with Hierarchical Structures Formed by Weak Intra-/Inter-chain Si/FC and van der Waals Interactions
}

\author{
By Takuma KAWABE, ${ }^{1}$ Masanobu NAITO, ${ }^{1}$ and Michiya FUJIKI ${ }^{1, *}$
}

\begin{abstract}
A semiflexible polysilane copolymer bearing 3,3,3-trifluoropropyl and $n$-decyl side chains formed an organogel in nonpolar organic solvents. Weak Si/FC interchain/intrachain interactions were formed between the Si main chain and fluoropropyl side chain, and acted as noncovalent crosslinks. Long alkyl ( $n$-decyl) groups acted as solvophilic moieties that effectively absorbed and retained organic solvent molecules. Furthermore, the relatively rigid main chain was also important for the gelation ability of the material. The existence of Si/FC interchain interactions was first demonstrated by careful IR measurement and analysis using a model silane molecule. Hierarchical structures at the meso- and nano-scale levels were successfully characterized by AFM, cryo-HR-TEM, IR, and ${ }^{19} \mathrm{~F}\left\{{ }^{29} \mathrm{Si}\right\}$-NOE NMR experiments.

KEY WORDS: Organogel / Polysilane / Weak Interactions / van der Waals Interaction / Fluorophilicity / Phase Separation /
\end{abstract}

Functional polymer gelators have received much interest due to their versatile applications, including actuators ${ }^{1}$ and absorbents for volatile organic compounds., ${ }^{2,3}$ Among these polymers, conjugated polymer based organogelators have received a great deal of interest because of their unique physical properties. For example, the introduction of ethanol and doping with iodine led to changes in the volume and visible-near IR absorption bands of poly(3-hexylthiophene) which was cross-linked with radical initiator dissolved in chloroform. ${ }^{4}$ However, both the compatibility of polymer chains with organic solvents and the density of covalent crosslinks play key roles in the gelation of these organogelators, ${ }^{2-4}$ which sometimes leads to difficulty in the molecular design of gelators with more elaborate functions.

On the other hand, various weak noncovalent interactions, e.g., $\mathrm{CH} / \pi, \mathrm{CH} / \mathrm{FC}, \mathrm{CH} / \mathrm{O}$, and $\mathrm{X} / \mathrm{X}$ (where $\mathrm{X}$ : $\mathrm{Cl}, \mathrm{Br}, \mathrm{S}$, and $\mathrm{Se}$ ), have recently been elucidated in these systems by X-ray diffraction analysis, vibrational spectroscopy, and precise computational calculations. ${ }^{5-10}$ Although weak noncovalent interactions are generally unstable, they are essential for constructing adaptable and hierarchical structures in nature. Self-assembly, smart functions, and conformation stabilization in these structures may result from the combination of multiple types of weak noncovalent interactions in small molecules, synthetic polymers, and biopolymers. Indeed, poly(di- $n$-butylsilane) and poly(di- $n$-pentylsilane) can form thermo-responsive organogels in aromatic solvents through a heating-cooling process. ${ }^{11}$ These organogels are essentially composed of two phases, 73 helical and trans-zigzag chain phases, presumably due to the formation of noncovalent crosslinks with the help of cooperative van der Waals interchain side chain packing interactions.

In previous papers, ${ }^{12-14}$ we demonstrated that two polysilane homopolymers (PSis) bearing fluoropropyl groups (PSi5 and PSi6, Scheme 1) can adopt a semiflexible helical conformation in solution at ambient temperature. In spite of chiral side chains with a very weak helix induction effect, PSi6 produced a semiflexible conformation with a single-handed $7_{3}$ helix, exhibiting an intense Cotton circular dichroism (CD) effect. Similarly, PSi5 without chiral side chains formed a CD silent, semiflexible chain composing an enantiomeric pair of $7_{3}$ helices. The origin of these thermally stable helical structures is the consequence of the cooperative behavior of weak $\mathrm{Si} / \mathrm{FC}$ intrachain interactions between the main chain and the trifluoropropyl side group. These novel properties and structures have already been shown by spectroscopic $\left({ }^{19} \mathrm{~F}\right.$ - and ${ }^{29} \mathrm{Si}-$ NMR, IR, UV, fluorescence, and CD), viscometric (MarkHouwink-Sakurada plot), and atomic force microscopy (AFM) studies. ${ }^{12-14}$

The magnitude of the $\mathrm{Si} / \mathrm{FC}$ interaction in PSi5 with $\sim 700$ Si repeat units was roughly estimated to be only $\sim 1$ cal per $\mathrm{Si}$ repeat unit, assuming that all the Si repeat units cooperatively contributed to the formation of the helical conformation. ${ }^{13}$ In other words, even this ultraweak intrachain interaction may be enough to form the stable helix by cooperatively adding up to $700 \mathrm{Si} / \mathrm{FC}$ intrachain units (in total, $\sim 0.7 \mathrm{kcal} / \mathrm{mol}$ ), which overcomes the fluctuating thermal force of $\sim 0.6 \mathrm{kcal} / \mathrm{mol}$. It was also already established that two polyisocyanates bearing alkyl side chains with a chiral H/D isotope effect in hexane at $25^{\circ} \mathrm{C}$ are able to adopt a semiflexible helical conformation with almost one-screw-sense, with a cooperative amplification mechanism of inter-side-chains by the product of the repeating numbers of $\sim 2000$ and an ultraweak chiral bias of $0.4-0.7 \mathrm{cal}$ per repeat unit. ${ }^{15}$

If such ultraweak $\mathrm{Si} / \mathrm{FC}$ intrachain interactions are applicable to the $\mathrm{Si} / \mathrm{FC}$ interchain interactions of polymers in organic solvents, then the interchain interactions may effectively act as noncovalent crosslinks to create an efficient polymeric organogelator. Because PSi5 has three fluorine atoms in the side group, one fluorine and the remaining two

\footnotetext{
${ }^{1}$ Graduate School of Materials Science, Nara Institute of Science and Technology, 8916-5, Takayama, Ikoma 630-0192, Japan

*To whom correspondence should be addressed (Tel: +81-743-72-6040, Fax: +81-743-72-6049, E-mail: fujkim @ms.naist.jp).
} 
<smiles>CC(C)C[SiH](C)O[Si](C)(C)CCC(F)(F)F</smiles>

PSi1<smiles>CC(C)C[Si](C)(C)CCC[SiH](C)CCC(F)(F)F</smiles>

PSi4

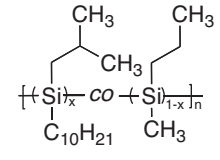

PSi2

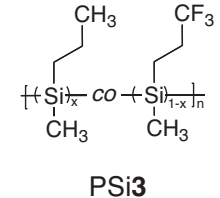

PSi3
Scheme 1. Chemical structures of polysilane copolymers and homo-polymers. PSi1: poly[(i-butyl- $n$-decylsilane $)_{x}-c o$-(methyl-3,3,3-trifluoropropylsilane) $\left.{ }_{1-x}\right]$, PSi1a; $x=0.56,1-x=0.44$, PSi1b; $x=$ $0.62,1-x=0.38$, PSi1c; $x=0.13,1-x=0.87$, PSi2: poly[( $i$-butyl- $n$-decylsilane $)_{0.27}$-co-(methyl- $n$-propylsilane $\left.)_{0.73}\right]$, PSi3: poly[(methyl- $n$-propylsilane) 0.52 -co-(methyl-3,3,3-trifluoropropylsilane $)_{0.48}$ ], PSi4: poly(i-butyl- $n$-decylsilane), PSi5: poly(methyl3,3,3-trifluoropropylsilane), PSi6: poly((S)-3,7-dimethyloctyl3,3,3-trifluoropropylsilane), Si7: di- $n$-hexylmethyl-3,3,3-trifluoropropylsilane.

fluorines may contribute to $\mathrm{Si} / \mathrm{FC}$ intrachain and interchain interactions, respectively (see, Figure 15 in ref 12). Indeed, AFM studies revealed that PSi5 casting from a dilute toluene solution on mica formed Y-shape branched rod-like bundle fibers, probably due to the expected $\mathrm{Si} / \mathrm{FC}$ interchain interactions between several PSi5 chains, in addition to individual rod-like fibers of $\sim 2000 \mathrm{~nm}$ in length due to the $\mathrm{Si} / \mathrm{FC}$ intrachain interactions. ${ }^{12}$

This paper demonstrates a successful approach to create a polymeric organogelator with hierarchical structures based on the above hypothesis. The PSi copolymer underwent gelation in nonpolar organic solvents with the help of plural noncovalent weak interactions in the absence of any heating/ cooling processes. This was demonstrated by AFM images of the networks at the mesoscopic scale, cryo-high-resolution transmission electron microscopy (HR-TEM) images of helix bundles at the nanoscopic scale, frequency shifts in IR spectra, and ${ }^{19} \mathrm{~F}\left\{{ }^{29} \mathrm{Si}\right\}$-NOE NMR experiments.

\section{RESULTS AND DISCUSSION}

First, to elucidate the effects of main chain stiffness and alkyl side chain length on the gelation ability of PSis, we chose $i$-butyl- $n$-decylsilane and methyl- $n$-propylsilane repeat units. ${ }^{16}$ These repeat units effectively produce semiflexible copolymers with a long alkyl group and flexible PSis with a short alkyl group, respectively. PSis employed in this study were classified as follows: ${ }^{16}$ PSi1, semiflexible PSi with $n$-decyl and 3,3,3trifluoropropyl groups; PSi2 and PSi4, semiflexible PSis with $n$-decyl groups; and PSi3 and PSi5, flexible PSis with n-propyl and 3,3,3-trifluoropropyl groups. All copolymers were prepared by Wurtz-type co-condensation of methyl-3,3,3-trifluoropropyldichlorosilane with the corresponding dialkyldichlorosilane with sodium in hot toluene or $n$-nonane. ${ }^{13}$ In addition, two homopolymers (PSi4 and PSi5) and a model silane molecule
(Si7) were prepared bearing trifluoropropyl and alkyl groups for comparison (see experimental section, Table II).

First, the appearance of the $10.0 \mathrm{wt} \%$ solutions of seven different PSis dissolved in thirteen different organic solvents was observed by the naked eye (Table I). The dielectric constants $(\varepsilon)$ of these solutions ranged from 1.8 ( $n$-pentane) to 32.7 (methanol), and observations were conducted at room temperature $\left(\sim 25^{\circ} \mathrm{C}\right)$. These PSis were dissolved in the organic solvents without any heating and/or sonication processes and were stored in the dark for $24 \mathrm{~h}$. Although PSi1a initially showed a relatively high solubility in nonpolar organic solvents, with $\varepsilon$ values between 1.8 (n-pentane) and 7.6 (tetrahydrofuran (THF)), ${ }^{17}$ the transparent solutions became translucent gels over the course of a $24 \mathrm{~h}$ incubation (Figure 3A, inset). PSi1b, PSi2, and PSi4 also had high solubilities in the nonpolar organic solvents with the same ranges of $\varepsilon$ values as PSi1a. However, they did not form organogels, even after a $24 \mathrm{~h}$ incubation period, and maintained their transparent viscous appearance. PSi1b only formed organogels in benzene and chloroform. PSi1c, PSi3, and PSi5 remained insoluble or immiscible (Figure 3B, inset). Thus, among seven different PSis, only PSila with both $n$-decyl and trifluoropropyl groups demonstrated an excellent gelation ability in various nonpolar organic solvents.

PSi1a, PSi1b, PSi1c, PSi3, and PSi5 all possess trifluoropropyl groups, but PSi2 and PSi4 do not. Note that PSi1a, PSi1b, PSi1c, and PSi2 are multi-block copolymers, as demonstrated by two ${ }^{29} \mathrm{Si}$ and/or two ${ }^{1} \mathrm{H}$ NMR signals due to the two types of blocks (see experimental section), although the block lengths (corresponding to $\mathrm{Si}$ repeat units) remain unclear. When the gelation behavior of PSi1a, PSi1b, PSi1c, and PSi3 in organic solvents was compared with that of PSi5, only PSi1a and PSi1b exhibited a gelation ability, while PSi1c, PSi3, and PSi5 did not. When the gelation behavior of semiflexible PSi1a, PSi1b, PSilc, and PSi4 in organic solvents was compared with that of flexible PSi3, only semiflexible copolymers and homopolymer showed a gelation ability and/or a highly viscosity.

As described above, PSila was able to form translucent gels in various nonpolar alkanes and aromatic solvents, as well as in polar chloroform and THF. However, PSilb exhibited an organogelation ability in benzene and chloroform only, while PSi1c did not. One possible explanation for this difference is that the ratio of alkylsilane/fluoroalkylsilane $(\mathrm{A} / \mathrm{F})$ repeating units may be an important factor affording a gelation ability and an effective microphase separation (see, Figure 4). For example, PSi1a (fraction 1) has an A/F ratio of 1.27 , while PSi1b (fraction 1) and PSi1c (fraction 1) have high and low $\mathrm{A} / \mathrm{F}$ ratios of 1.63 and 0.15 , respectively.

Note that the value of $\Delta H$ responsible for the sol-gel transition appears to very small. Indeed we observed no detectable differences in FT-IR spectra of PSila in film in the $40-120^{\circ} \mathrm{C}$ range, and UV absorption spectra of PSi1a in toluene $\left(\sim 10^{-5} \mathrm{M}\right.$ as $\mathrm{Si}$ repeat unit $)$ in the $25-95^{\circ} \mathrm{C}$.

Also, the viscosity index given by the Mark-HouwinkSakurada plot tells us the degree of chain coiling of polymer at a 
Table I. Appearance of PSis dispersed in various organic solvents

\begin{tabular}{|c|c|c|c|c|c|c|c|c|}
\hline Solvent & $\begin{array}{c}\text { Dielectric } \\
\text { constant }(\varepsilon)^{\mathrm{b})}\end{array}$ & $\begin{array}{c}\mathrm{PSi} \\
\mathbf{1 a}\end{array}$ & $\begin{array}{l}\mathrm{PSi} \\
\mathbf{1 b}\end{array}$ & $\begin{array}{c}\mathrm{PSi} \\
\mathbf{1 c}\end{array}$ & $\begin{array}{c}\mathrm{PSi} \\
\mathbf{2}\end{array}$ & $\begin{array}{c}\mathrm{PSi} \\
\mathbf{3}\end{array}$ & $\begin{array}{c}\mathrm{PSi} \\
\mathbf{4} \\
\end{array}$ & $\begin{array}{c}\mathrm{PSi} \\
\mathbf{5} \\
\end{array}$ \\
\hline$n$-Pentane & $\begin{array}{c}1.84 \\
\left(20^{\circ} \mathrm{C}\right)\end{array}$ & $\mathrm{G}$ & V & 1 & V & $\mathrm{IM}$ & V & I \\
\hline$n$-Hexane & $\begin{array}{c}1.88 \\
\left(25^{\circ} \mathrm{C}\right)\end{array}$ & $\mathrm{G}$ & V & 1 & V & $\mathrm{IM}$ & V & I \\
\hline$n$-Octane & $\begin{array}{c}1.95 \\
\left(20^{\circ} \mathrm{C}\right)\end{array}$ & $\mathrm{G}$ & V & 1 & V & 1 & V & 1 \\
\hline$n$-Decane & $\begin{array}{c}1.99 \\
\left(20^{\circ} \mathrm{C}\right)\end{array}$ & $\mathrm{G}$ & V & 1 & V & 1 & V & I \\
\hline Cyclohexane & $\begin{array}{c}2.02 \\
\left(20^{\circ} \mathrm{C}\right)\end{array}$ & $\mathrm{G}$ & V & 1 & V & $\mathrm{IM}$ & V & I \\
\hline Benzene & $\begin{array}{c}2.27 \\
\left(25^{\circ} \mathrm{C}\right)\end{array}$ & $\mathrm{G}$ & $\mathrm{G}$ & I & V & $\mathrm{IM}$ & V & 1 \\
\hline Toluene & $\begin{array}{c}2.38 \\
\left(25^{\circ} \mathrm{C}\right)\end{array}$ & $\mathrm{G}$ & V & I & V & $\mathrm{IM}$ & V & I \\
\hline Chloroform & $\begin{array}{c}4.81 \\
\left(20^{\circ} \mathrm{C}\right)\end{array}$ & $\mathrm{G}$ & $\mathrm{G}$ & $\mathrm{S}$ & V & $\mathrm{S}$ & V & IM \\
\hline THF & $\begin{array}{c}7.58 \\
\left(25^{\circ} \mathrm{C}\right)\end{array}$ & $\mathrm{G}$ & V & $S$ & V & $S$ & V & $S$ \\
\hline Benzotrifluoride & $\begin{array}{c}9.04 \\
\left(25^{\circ} \mathrm{C}\right)\end{array}$ & SW & V & $\mathrm{S}$ & I & $\mathrm{S}$ & 1 & $S$ \\
\hline 2-Propanol & $\begin{array}{c}19.92 \\
\left(25^{\circ} \mathrm{C}\right)\end{array}$ & I & 1 & I & I & 1 & 1 & I \\
\hline Ethanol & $\begin{array}{c}24.55 \\
\left(25^{\circ} \mathrm{C}\right)\end{array}$ & I & I & I & I & 1 & 1 & I \\
\hline Methanol & $\begin{array}{c}32.66 \\
\left(25^{\circ} \mathrm{C}\right)\end{array}$ & I & I & I & I & I & I & I \\
\hline
\end{tabular}

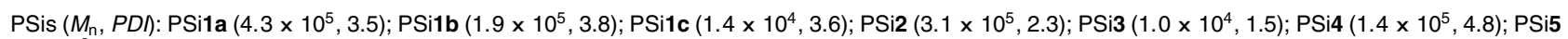
$\left(7.6 \times 10^{3}, 1.3\right)$. a Abbreviations: SW, swell; V, viscous solution; G, gel; I, insoluble; IM, immiscible; S, Solution. 10.0 wt $\%$ of specimen were prepared in a $1 \mathrm{~mL}$ microtube, and stored in the dark for $24 \mathrm{~h}$ at room temperature. ${ }^{b}$ ref. 17.

given condition (in this case, THF at $40{ }^{\circ} \mathrm{C}$ ). ${ }^{16}$ Among PSi1a, PSi1b, PSi2, PSi3, and PSi4, semiflexible PSi1a and PSi1b only resulted in formation of organogel and/or highly viscous states. It is thus possible that the semiflexible PSis with multiblocks may facilitate the formation of the crosslink by the help of the weak attractive interchain interactions with a minimal change in their conformation between sol and gel states.

These results led to the conclusion that in order to be a good organogelator, PSi should have (i) fluoropropyl groups, (ii) multi-block structures, (iii) longer $n$-decyl groups, (iv) an appropriate A/F ratio, (v) semiflexible conformation, and (vi) a subtle balance between these factors.

Indeed, it is well-known that multi-block polymers without any specific functional groups often form organogels due to microphase separation and the subsequent physical bridging reflecting the different solubility of each polymer block. ${ }^{18}$ For example, ABA triblock copolymer with high molecular weights, composed of polystyrene endblocks and a poly(ethylene/butylene) midblock, was able to form an organogel in liquid paraffin. ${ }^{18}$ The gelation arises from a difference in solubility between the endblocks and the midblock, resulting in the formation of micellar aggregates. In these aggregates, the endblocks formed micelles while the midblocks acted as bridges between the micelles. Actually, the thermo-responsive organogelation of poly(di- $n$-alkylsilane)s may be related to an ability to produce two types of block-like structures $\left(7_{3}\right.$ helical and trans-zigzag). ${ }^{11}$
Similarly, a mixture of two ammonium amphiphiles undergoes microphase separation. ${ }^{19}$ Triple-chain ammonium amphiphiles with fluorocarbons cannot mix with the corresponding amphiphiles with hydrocarbon in bilayer membranes in water, and spontaneously undergoes phase separation in the same membrane films. ${ }^{19}$ The gelation mechanism of the multi-block PSi copolymers containing fluoroalkyl groups may be related to a greater difference in miscibility between the fluoroalkylsilane blocks and alkylsilane blocks, due to a subtle balance in these copolymers between fluorophilic and fluorophobic interactions. Also, friction force mode AFM experiments demonstrated that fluorocarbon and hydrocarbon species undergo a microphase separation in LB films. ${ }^{20}$

Thus, the great difference in miscibility between the fluoroalkylsilane and alkylsilane blocks in the multi-block PSi copolymers may effectively promote $\mathrm{Si} / \mathrm{FC}$ intrachain and interchain interactions in the gelation process. It is hence possible that specific structures in organogel are stabilized with an amplification mechanism by the product of the weak $\mathrm{Si} / \mathrm{FC}$ attractive forces and the numbers of the $\mathrm{Si} / \mathrm{FC}$ units in microphases.

These considerations led to the hypothesis that $n$-decyl and fluoropropyl groups might be acting (a) as solvophilic moieties that effectively absorb and retain organic solvent molecules and (b) as crosslinkers among polymer chains via $\mathrm{Si} / \mathrm{FC}$ intrachain/interchain interactions. Furthermore, the PSi organogel formed in toluene did not show any sol-gel transition in 


\begin{tabular}{|c|c|c|c|c|c|c|c|c|}
\hline PSi & Fraction & $\begin{array}{c}\text { Feed molar } \\
\text { fraction (MA } \\
(\mathrm{mol}) / \mathrm{MF}(\mathrm{mol}))\end{array}$ & $\begin{array}{l}\text { Obtained molar } \\
\text { fraction (MA } \\
(\mathrm{mol}) / \mathrm{MF}(\mathrm{mol}))\end{array}$ & $\begin{array}{c}M_{\mathrm{n}} \\
\left(\times 10^{-5}\right)\end{array}$ & $P D I$ & $\begin{array}{c}\text { Yield } \\
(\%)\end{array}$ & $\alpha$ & Remarks $\left(M_{\mathrm{w}}\right)$ \\
\hline \multirow[t]{5}{*}{ PSi1a } & 1 & $0.50 / 0.50$ & $0.56 / 0.44$ & 4.3 & 3.5 & 2.7 & 0.91 & $2.6 \times 10^{5} \leq M_{\mathrm{w}} \leq 3.3 \times 10^{6}$ \\
\hline & 2 & $0.50 / 0.50$ & - & 4.8 & 2.7 & 3.2 & - & - \\
\hline & 3 & $0.50 / 0.50$ & $0.57 / 0.43$ & 2.9 & 2.5 & 4.1 & - & - \\
\hline & 4 & $0.50 / 0.50$ & - & 1.8 & 2.0 & 1.1 & - & - \\
\hline & 5 & $0.50 / 0.50$ & $0.55 / 0.45$ & 1.0 & 1.9 & 0.9 & - & - \\
\hline \multirow[t]{3}{*}{ PSi1b } & 1 & $0.75 / 0.25$ & $0.62 / 0.38$ & 1.9 & 3.8 & 4.8 & 1.04 & $5.6 \times 10^{5} \leq M_{w} \leq 2.4 \times 10^{6}$ \\
\hline & 2 & $0.75 / 0.25$ & - & 1.1 & 2.3 & 0.9 & - & - \\
\hline & 3 & $0.75 / 0.25$ & - & 0.30 & 1.5 & 12 & - & - \\
\hline \multirow[t]{2}{*}{ PSi1c } & 1 & $0.25 / 0.75$ & $0.13 / 0.87$ & 0.14 & 3.6 & 5.0 & - & - \\
\hline & 2 & $0.25 / 0.75$ & - & 0.058 & 1.5 & 2.7 & - & - \\
\hline \multirow[t]{14}{*}{ PSi2 } & 1 & $0.50 / 0.50$ & - & 10 & 3.6 & 0.6 & - & - \\
\hline & 2 & $0.50 / 0.50$ & - & 10 & 2.3 & 3.2 & - & - \\
\hline & 3 & $0.50 / 0.50$ & $0.27 / 0.73$ & 3.1 & 2.3 & 1.9 & 1.09 & $7.9 \times 10^{4} \leq M_{\mathrm{w}} \leq 8.0 \times 10^{5}$ \\
\hline & 4 & $0.50 / 0.50$ & - & 2.4 & 1.8 & 1.5 & - & - \\
\hline & 5 & $0.50 / 0.50$ & - & 2.0 & 1.8 & 1.4 & - & - \\
\hline & 6 & $0.50 / 0.50$ & - & 1.6 & 1.5 & 1.1 & - & - \\
\hline & 7 & $0.50 / 0.50$ & $0.42 / 0.58$ & 1.2 & 1.7 & 3.3 & - & - \\
\hline & 8 & $0.50 / 0.50$ & - & 0.98 & 1.4 & 1.2 & - & - \\
\hline & 9 & $0.50 / 0.50$ & - & 0.75 & 1.7 & 1.4 & - & - \\
\hline & 10 & $0.50 / 0.50$ & - & 0.48 & 1.8 & 2.3 & - & - \\
\hline & 11 & $0.50 / 0.50$ & - & 0.39 & 1.5 & 2.9 & - & - \\
\hline & 12 & $0.50 / 0.50$ & - & 0.34 & 1.5 & 1.8 & - & - \\
\hline & 13 & $0.50 / 0.50$ & - & 0.30 & 1.4 & 1.9 & - & - \\
\hline & 14 & $0.50 / 0.50$ & - & 0.21 & 1.5 & 0.9 & - & - \\
\hline \multirow[t]{2}{*}{ PSi3 } & 1 & $0.50 / 0.50$ & $0.52 / 0.48$ & 0.10 & 1.5 & 12 & 0.63 & $2.6 \times 10^{4} \leq M_{\mathrm{w}} \leq 2.3 \times 10^{5}$ \\
\hline & 2 & $0.50 / 0.50$ & - & 0.11 & 1.5 & 0.6 & - & - \\
\hline \multirow[t]{10}{*}{ PSi4 } & 1 & - & - & 11 & 2.2 & 2.7 & - & - \\
\hline & 2 & - & - & 2.8 & 5.2 & 2.0 & - & - \\
\hline & 3 & - & - & 2.1 & 3.9 & 0.2 & - & - \\
\hline & 4 & - & - & 1.4 & 4.8 & 1.1 & 1.10 & $5.7 \times 10^{5} \leq M_{\mathrm{w}} \leq 1.0 \times 10^{6}$ \\
\hline & 5 & - & - & 1.6 & 1.6 & 1.2 & - & - \\
\hline & 6 & - & - & 0.85 & 1.3 & 1.2 & - & - \\
\hline & 7 & - & - & 0.57 & 1.2 & 1.7 & - & - \\
\hline & 8 & - & - & 0.38 & 1.2 & 1.2 & - & - \\
\hline & 9 & - & - & 0.30 & 1.2 & 0.8 & - & - \\
\hline & 10 & - & - & 0.25 & 1.2 & 0.6 & - & - \\
\hline \multirow[t]{3}{*}{ PSi5 } & 1 & - & - & 0.17 & 1.6 & 1.6 & - & - \\
\hline & 2 & - & - & 0.13 & 1.2 & 0.7 & - & - \\
\hline & 3 & - & - & 0.076 & 1.3 & 13 & - & - \\
\hline
\end{tabular}

For the gelation test, PSi1a (fraction 1), PSi1b (fraction 1), PSi1c (fraction 1), PSi2 (fraction 3), PSi3 (fraction 1), PSi4 (fraction 4), and PSi5 (fraction 3) were used.

the range of room temperature to $\sim 100^{\circ} \mathrm{C}$. This result indicates that the most significant property of PSi organogels leads to the maintenance of the gel state over a wide range of temperatures. The following sections focus on PSila in order to elucidate the gelation mechanism in detail.

In order to elucidate the gelation mechanism as well as to prove the coexistence of $\mathrm{Si} / \mathrm{FC}$ intrachain/interchain interactions in PSila gels, we initially measured the NOE ${ }^{19} \mathrm{~F}\left\{{ }^{29} \mathrm{Si}\right\}$ NMR spectrum of PSi1a in dilute THF- $d_{8}(\sim 1 \times$ $10^{-2} \mathrm{M}$ as $\mathrm{Si}$ repeat unit). It was expected that $\mathrm{Si} / \mathrm{FC}$ intrachain interactions are prevalent, while $\mathrm{Si} / \mathrm{FC}$ interchain interactions are negligible.

From a marked difference in the NOE ${ }^{19} \mathrm{~F}$ spectrum of PSi1a copolymer (Figure 1), the existence of Si/FC intrachain interactions was evident. A clear negative NOE attenuation was observed in the ${ }^{19} \mathrm{~F}$ NMR spectrum upon irradiation of ${ }^{29} \mathrm{Si}$ resonance at $-31.2 \mathrm{ppm}$, indicating that the closest throughspace distance between $\mathrm{Si}$ and F should be within $c a .0 .5 \mathrm{~nm}$. Similarly, an NOE attenuation had already been observed in the NOE ${ }^{19} \mathrm{~F}$ spectrum of PSi5 in toluene. ${ }^{13}$ Thus, it was shown that the Si/FC intrachain interactions exist in PSi1a copolymers as well as in PSi5 homopolymer.

The coexistence of the Si/FC interchain and van der Waals intrachain/interchain interactions in the PSi1a gel was strongly suggested by the following FT-IR spectroscopy.

Figure $2 \mathrm{~A}$ shows the asymmetric $\mathrm{CH}_{2} \quad\left(v_{\text {as }}\left(\mathrm{CH}_{2}\right)\right)$ and symmetric $\mathrm{CH}_{2}\left(v_{\mathrm{s}}\left(\mathrm{CH}_{2}\right)\right)$ stretching bands of alkyl chains. Although the $v_{\text {as }}\left(\mathrm{CH}_{2}\right)$ and $v_{\mathrm{s}}\left(\mathrm{CH}_{2}\right)$ bands of the PSi3 film appeared at 2930 and $2872 \mathrm{~cm}^{-1}$, respectively, the corresponding bands of the PSila gel in toluene were minimally 


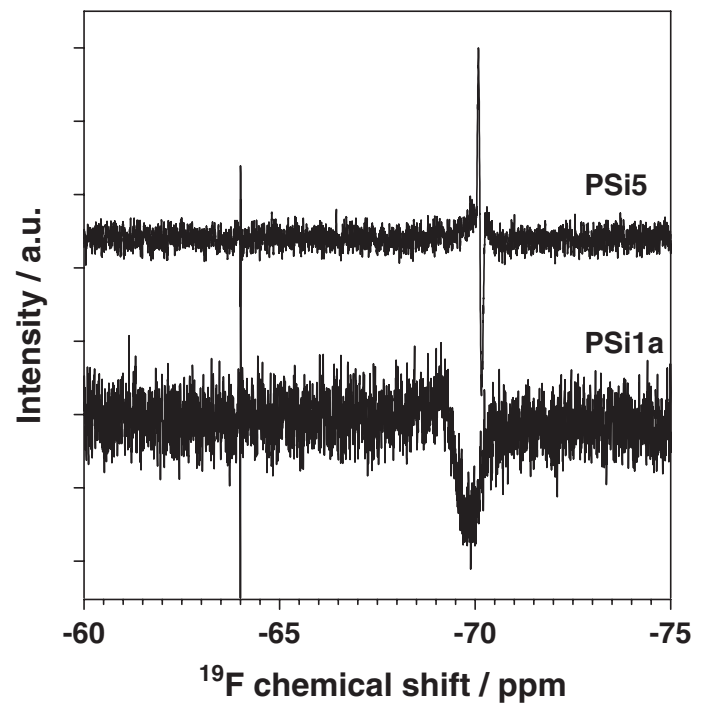

Figure 1. ${ }^{19} \mathrm{~F}\left\{{ }^{29} \mathrm{Si}\right\}-N M R$ NOE spectra of PSi1a $\left(M_{\mathrm{n}}=4.3 \times 10^{5}\right)$ and PSi5 $\left(M_{\mathrm{n}}=1.7 \times 10^{4}\right)$ in THF- $d_{8}$.

redshifted, by $5 \mathrm{~cm}^{-1}$ to $2925 \mathrm{~cm}^{-1}$, and significantly redshifted, by $17 \mathrm{~cm}^{-1}$ to $2855 \mathrm{~cm}^{-1}$, respectively. These redshifted $v_{\mathrm{as}}\left(\mathrm{CH}_{2}\right)$ and $v_{\mathrm{s}}\left(\mathrm{CH}_{2}\right)$ bands indicate a marked decrease in the fluidity of the alkyl chains. ${ }^{21}$ Thus, $n$-decyl groups in the gel state were able to spontaneously self-assemble, resulting in efficiently well-organized packing structures via van der Waals interactions, both interchain/intrachain, whereas the shorter $n$-propyl group of PSi3 maintained its high chain mobility even in cast film.

Note that the asymmetric C-F $\left(v_{\mathrm{as}}(\mathrm{C}-\mathrm{F})\right)$ and symmetric $\mathrm{C}-\mathrm{F}$ $\left(v_{\mathrm{s}}(\mathrm{C}-\mathrm{F})\right)$ stretching vibration bands of PSila gel in toluene $\left(\sim 10^{-1} \mathrm{M}\right.$ as $\mathrm{Si}$ repeat unit) showed unexpected frequency shifts. Figure $2 \mathrm{~B}$ shows absorption bands of $v_{\mathrm{as}}(\mathrm{C}-\mathrm{F})$ and $v_{\mathrm{s}}(\mathrm{C}-$ F) bands from the fluoroalkyl group. ${ }^{12,13}$ Although the $v_{\text {as }}(\mathrm{C}-\mathrm{F})$ and $v_{\mathrm{s}}(\mathrm{C}-\mathrm{F})$ bands of the PSi5 film clearly appeared at $1210 \mathrm{~cm}^{-1}$ and $1125 \mathrm{~cm}^{-1}$, respectively, those from the PSi1a gel in toluene were blueshifted, by $4 \mathrm{~cm}^{-1}$ and $5 \mathrm{~cm}^{-1}$, respectively, to $1214 \mathrm{~cm}^{-1}$ and $1130 \mathrm{~cm}^{-1}$. $\mathrm{PSi3}$, with no gelation ability, also showed blueshifted $v_{\mathrm{as}}(\mathrm{C}-\mathrm{F})$ and $v_{\mathrm{s}}(\mathrm{C}-\mathrm{F})$ bands at 1213 and $1126 \mathrm{~cm}^{-1}$, respectively. The origin of the slight blue shifts in the $v_{\mathrm{as}}(\mathrm{C}-\mathrm{F})$ and $v_{\mathrm{s}}(\mathrm{C}-\mathrm{F})$ bands may be explained by analogy to non-classical hydrogen bonds. 5,6 Several current studies suggest that weak $\mathrm{X}-\mathrm{H} / \mathrm{Y}$ hydrogen bond formation gives rise to a blue-shift in the X-H stretching frequency, resulting in a shortened $\mathrm{X}-\mathrm{H}$ bond. ${ }^{7}$ This unique phenomenon occurs only in weak hydrogen bonds, in which the re-hybridization factor responsible for the shortened X-H bond is more pronounced than hyper-conjugation, resulting in the lengthening of the X-H bond. ${ }^{10}$ Indeed, blueshifted $v_{\text {as }}(\mathrm{C}-\mathrm{F})$ and $v_{\mathrm{s}}(\mathrm{C}-\mathrm{F})$ bands of PSi5 were also found in cast film, here resulting from weak $\mathrm{Si} / \mathrm{FC}$ interactions. ${ }^{13}$ The unusual blueshifted $v_{\mathrm{as}}(\mathrm{C}-\mathrm{F})$ and $v_{\mathrm{s}}(\mathrm{C}-\mathrm{F})$ bands from the PSi1a copolymer gel implied the possibility of $\mathrm{Si} / \mathrm{FC}$ interactions.

However, it is still unclear whether the unexpected slight blueshifts in the $v_{\mathrm{as}}(\mathrm{C}-\mathrm{F})$ and $v_{\mathrm{s}}(\mathrm{C}-\mathrm{F})$ bands of PSila gel come
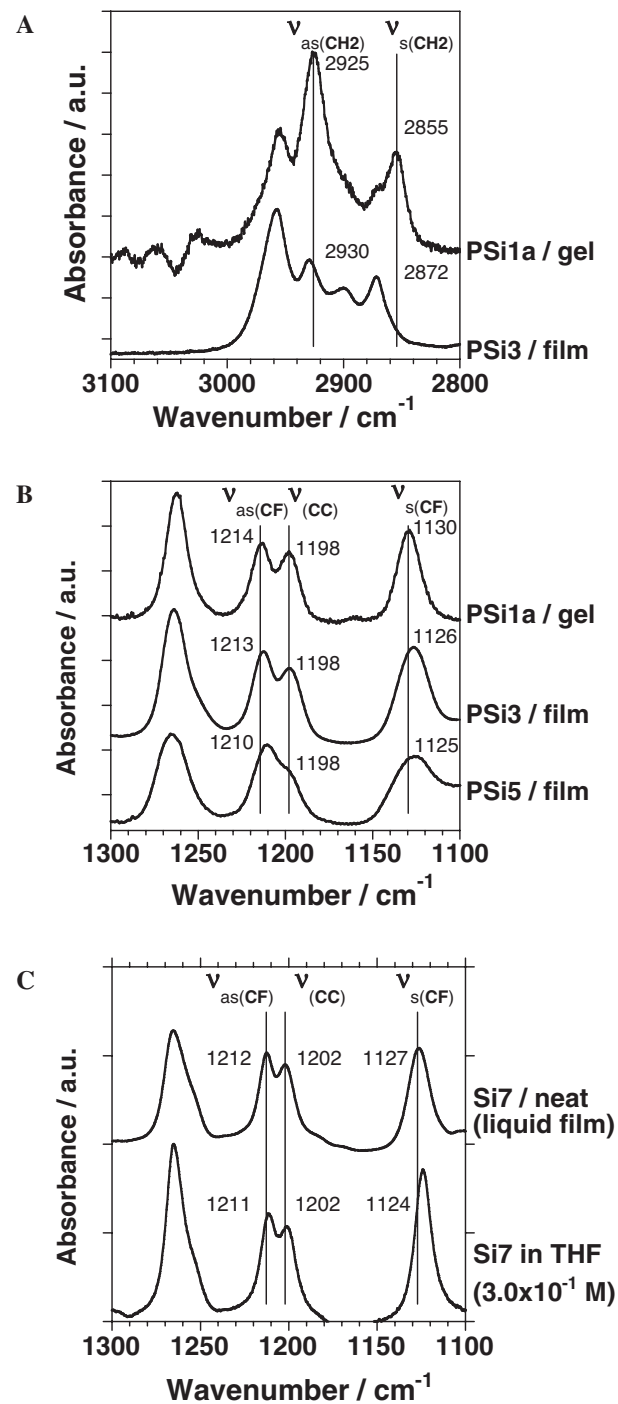

Figure 2. FT-IR spectra of PSis and Si7 in various states. (A) Absorption regions for $\mathrm{CH}_{2}$ asymmetric $\left(3000-2900 \mathrm{~cm}^{-1}\right)$ and $\mathrm{CH}_{2}$ symmetric stretching $\left(2870-2830 \mathrm{~cm}^{-1}\right)$. (B) Absorption regions for CF asymmetric $\left(1230-1180 \mathrm{~cm}^{-1}\right)$ and CF symmetric stretching $\left(1130-1110 \mathrm{~cm}^{-1}\right)$, Conditions: PSis $\left(M_{\mathrm{n}}, \mathrm{PDI}\right)$ : PSi1a/gel $(\sim 1 \mathrm{x}$ $10^{-1} \mathrm{M}$ as $\mathrm{Si}$ repeat uni) $\left(4.3 \times 10^{5}, 3.5\right)$; PSi3/film $\left(1.0 \times 10^{4}\right.$, 1.5); PSi5/film $\left(1.7 \times 10^{4}, 1.6\right)$. (C) Absorption regions for $\mathrm{CF}$ asymmetric $\left(1230-1180 \mathrm{~cm}^{-1}\right)$ and CF symmetric stretching $\left(1130-1110 \mathrm{~cm}^{-1}\right)$, Conditions: Si7: liquid neat film, in THF solution $\left(3.0 \times 10^{-1} \mathrm{M}\right)$.

from the weak $\mathrm{Si} / \mathrm{FC}$ interchain and/or intrachain interactions when compared to those of PSi3 and PSi5 films. This is because it is impossible to detect IR signals with a high $\mathrm{S} / \mathrm{N}$ ratio from PSila in very dilute solution (less than $\sim 10^{-2} \mathrm{M}$ as Si repeat units) due to the limited sensitivity of our FT-IR spectrometer along with the relatively high resolution of $0.5 \mathrm{~cm}^{-1}$.

In order to solve this problem and answer this question, IR spectra of Si7 molecule were measured in the liquid neat film and THF solution states $\left(\sim 10^{-1} \mathrm{M}\right)$ (Figure $2 \mathrm{C}$ ). Note that $\mathrm{Si7}$ is regarded as a model molecule of PSi5 and PSila with the trifluoropropyl group. The $v_{\mathrm{as}}(\mathrm{C}-\mathrm{F})$ and $v_{\mathrm{s}}(\mathrm{C}-\mathrm{F})$ bands of $\mathrm{Si7}$ in 

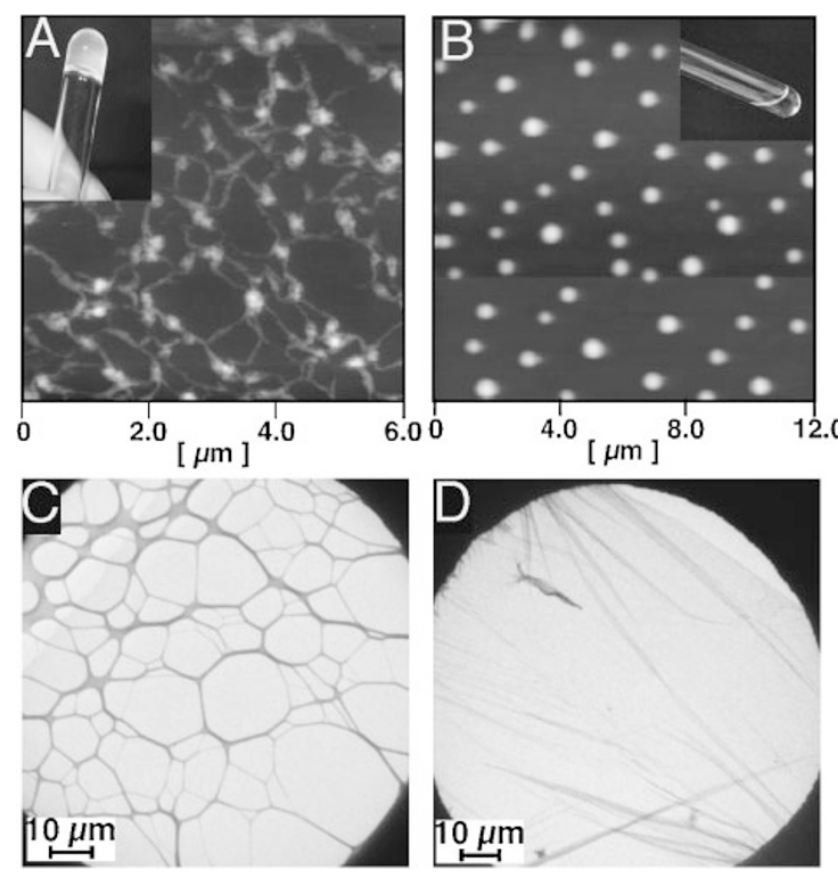

Figure 3. Typical AFM images from (A) PSi1a $\left(M_{n}=4.3 \times 10^{5}\right)$ and (B) PSi3 solution $\left(M_{n}=1.0 \times 10^{4}\right)$ on mica. Cryo-HR-TEM images at $-140^{\circ} \mathrm{C}$ from (C) PSi1a gel in toluene $\left(M_{\mathrm{n}}=4.3 \times\right.$ $\left.10^{5}\right)$ and (D) PSi4 toluene solution (1.0 wt $\left.\%, M_{\mathrm{n}}=1.4 \times 10^{5}\right)$.

the liquid neat film appeared at $1212 \mathrm{~cm}^{-1}$ and $1127 \mathrm{~cm}^{-1}$, respectively, and these bands were blueshifted by $1 \mathrm{~cm}^{-1}$ and $3 \mathrm{~cm}^{-1}$, respectively, when compared to those from $\mathrm{Si7}$ in THF.

Here, Si7 in THF is a model structure without any $\mathrm{Si} / \mathrm{FC}$ intrachain and interchain interactions. Actually, variable temperature dependency of ${ }^{29} \mathrm{Si}\{\mathrm{H}\} \mathrm{NMR}$ of $\mathrm{Si} 7$ in $\mathrm{CDCl}_{3}$ $\left(\sim 10^{-2} \mathrm{M}\right)$ in the range of -30 to $25^{\circ} \mathrm{C}$ showed no detectable change in ${ }^{29} \mathrm{Si} \mathrm{NMR}$ chemical shift. This suggested the absence of $\mathrm{Si} / \mathrm{FC}$ inter molecular and intramolecular interactions in $\mathrm{CDCl}_{3}$ and probably in THF. On the other hand, Si7 in neat liquid film is a model exhibiting $\mathrm{Si} / \mathrm{FC}$ intrachain and interchain interactions. These slight blueshifts in the $v_{\text {as }}(\mathrm{C}-\mathrm{F})$ and $v_{\mathrm{s}}(\mathrm{C}-\mathrm{F})$ bands could be evidence of $\mathrm{Si} / \mathrm{FC}$ intrachain and interchain interactions.

These IR measurements of Si7 led to the idea that slight blueshifts $\left(c a .4-5 \mathrm{~cm}^{-1}\right)$ in the $v_{\text {as }}(\mathrm{C}-\mathrm{F})$ and $v_{\mathrm{s}}(\mathrm{C}-\mathrm{F})$ bands of the PSila gel might originate from the $\mathrm{Si} / \mathrm{FC}$ interchain interactions along with intrachain interactions existing in the organogel. High-level theoretical calculations using appropriate model compounds might be needed in order to further understand the nature and magnitude of Si/FC intrachaininterchain interactions, which are very new attractive ultraweak forces between heteroatoms. This subject will be of particular interest among theoreticians.

Consequently, it was confirmed that the formation of PSi1a organogels results from a combination of van der Waals interactions between $n$-decyl groups and $\mathrm{Si} / \mathrm{FC}$ intrachaininterchain interactions between fluoroalkyl groups and the $\mathrm{Si}$ main chain.
Hanabusa et al. previously demonstrated the importance of a subtle balance between hydrophobic and hydrogen bonding interactions in many small molecular gelators. ${ }^{22}$ Similarly, a proper combination of several weak noncovalent interactions in polymer gels is of particular importance for designing network structures with a high degree of structural adaptability. For PSi based gels, the fluoroalkyl to long alkyl group ratio, multiblock structures with a high immiscibility, and main chain stiffness may be crucial when several weak noncovalent interactions are used to design functional organogels.

Finally, the unique hierarchical topology responsible for PSi1a gelation was directly visualized by AFM and HR-TEM. Figure $3 \mathrm{~A}$ and $3 \mathrm{~B}$ show AFM images of PSila and PSi3 cast from toluene solution on freshly cleaved mica. Highly entangled PSila chains produced cross-linked network structures, while PSi3 only formed dot-like structures. This significant difference in PSi topology may result from the degree of PSi main chain stiffness. Semi-flexible PSi1a chains, with their long gyration length in solution, were effectively entangled among several polymer chains, followed by the formation of highly cross-linked network structures. On the other hand, random-coiled flexible PSi3, with its very short gyration length, adopted dot-like forms in place of network structures. These dot-like forms minimize the surface free energy by avoiding contact with air, which acts as a poor solvent. $^{23}$

HR-TEM observations revealed more detailed structures of the PSi1a organogel. Figure 3C shows the cryo-HR-TEM image of PSila cast from toluene gel. Highly cross-linked network structures were observed. On the other hand, cryo-HRTEM images of PSi4 cast from toluene solution (1.0 wt \%) did not show gelation ability, but showed homogeneous films instead (Figure 3D). These results suggest that the highly cross-linked network structures originated from the PSi organogels.

An enlarged picture of the network structure clearly shows domains with highly oriented bundles on the order of $\mathrm{nm}$ (Figure 4A). Each bundle contains chain-like polymers. In addition, magnified TEM images of Figure 4A (Figure 4B and 4C) suggest that several domains stack on each other, resulting in multilayer structures. Note that the widths of the polymers varies, but the width is fairly consistent within particular bundles (Figure 4A). From cross-sectional analysis, the widths of the widest and narrowest chains were calculated to be $2.52 \pm 0.57 \mathrm{~nm}$ (Figure 4B) and $1.20 \pm 0.35 \mathrm{~nm}$ (Figure 4C), respectively. From computational calculations (Materials Studio 4.0 with PCFF as a force field, Accelrys Inc., San Diego CA), the estimated molecular diameters of PSi4 and PSi5 were 2.65 and $1.18 \mathrm{~nm}$, respectively. Thus, the wider and narrower chains in the domains were almost identical to block-like PSi4 and PSi5 sequences in PSi1a, respectively (Figure 4A).

It was previously reported that PSis prepared by Wurtz-type co-condensation of methyl-3,3,3-trifluoropropyldichlorosilane and dialkyldichlorosilane with sodium may be multi-block copolymers with long sequences. ${ }^{24}$ Similarly, PSi1a appears to 

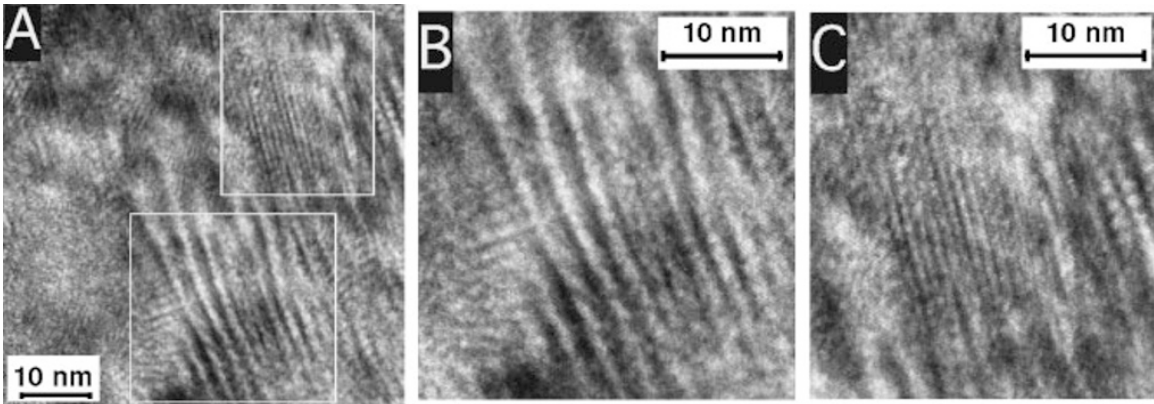

Figure 4. Cryo-HR-TEM images at $-140^{\circ} \mathrm{C}$ from (A) PSi1a toluene solution $\left(1.0 \mathrm{wt} \%, M_{n}=4.3 \times 10^{5}\right)$ on a carbon film coated microgrid. (B) Enlarged image of (A) (left, bottom), and (C) enlarged image of (A) (right, upper).
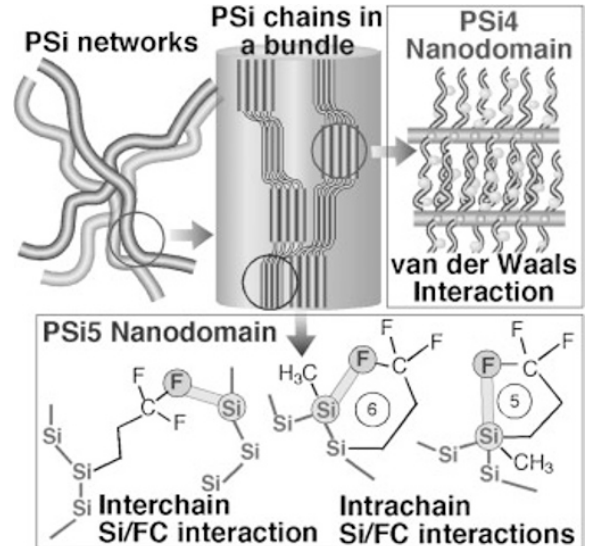

Figure 5. A proposed model for the gelation of PSi1a through solvophilic long alkyl chains and Si/FC interchain-intrachain interactions between the fluoropropyl group and the Si main chain.

consist of relatively long PSi4 and PSi5 sequences. Therefore, PSi4 and PSi5 blocks spontaneously caused a phase separation to form the nanodomains when PSi1a was dissolved in organic solvents. Ultraweak Si/FC intrachain/ interchain interactions were efficiently amplified in the nanodomains composed of PSi5 sequences, and were strong enough to connect with the polymer chains. The self-assembled $n$-decyl groups in the nanodomain composed of PSi4 sequences formed frameworks of nanocages which may be responsible for the absorption and retention of nonpolar organic solvent molecules. Consequently, highly cross-linked PSi network structures were formed by entangling self-assembled PSi bundles.

Finally, Figure 5 showed a proposed model for the gelation of PSila through solvophilic long alkyl chains and $\mathrm{Si} / \mathrm{FC}$ interchain and intrachain interactions between the fluoropropyl group and the Si main chain.

\section{EXPERIMENTAL}

\section{Measurements}

The number-average molecular weight $\left(M_{\mathrm{n}}\right)$ and weightaverage molecular weight of the polymers $\left(M_{\mathrm{w}}\right)$ were deter- mined using gel permeation chromatography at $40^{\circ} \mathrm{C}$ based on a calibration with polystyrene standards (Shimadzu A10 instruments, PLgel $10 \mathrm{~mm}$ mixed-B as a column, and HPLCgrade tetrahydrofuran as eluent). The intrinsic viscositymolecular weight relationship was performed using Viscotek T60A detector and RID-10A (Shimadzu) equipped with TSKgel $\mathrm{GMH}_{\mathrm{HR}}-\mathrm{H}$ (20) (Tosoh) at $40^{\circ} \mathrm{C}$ using $\mathrm{THF}$ as an eluent. The refractive index and the relative viscosity of the eluate were simultaneously recorded with this apparatus. Standard polystyrene of $M_{\mathrm{w}}(122,000)$ (American Polymer Standards) was used to calculate the apparatus distinctive constant to evaluate the refractive index increment $\mathrm{dn} / \mathrm{dc}$ of the polymer. UV absorption spectra were recorded on a JASCO V-550 spectrophotometer at room temperature. FT-IR spectra were obtained on a Horiba FT-730, using a liquid cell of $\mathrm{KBr}$ substrate with polysilane toluene gel, and by casting a tetrahydrofuran solution of polysilane on a $\mathrm{KBr}$ substrate.

${ }^{1} \mathrm{H}$ and ${ }^{13} \mathrm{C}\left\{{ }^{1} \mathrm{H}\right\}$ NMR spectra were measured in $\mathrm{CDCl}_{3}$ with a JEOL JNM-LA400 spectrometer using tetramethylsilane $(\delta 0.0 \mathrm{ppm})$ as an internal standard. ${ }^{29} \mathrm{Si}\left\{{ }^{1} \mathrm{H}\right\}$ NMR spectra were measured with a JEOL JNM-LA400 spectrometer in $\mathrm{CDCl}_{3}$ and THF- $d_{8}$ using tetramethylsilane $(\delta 0.0 \mathrm{ppm})$ and hexamethyldisilane $(\delta-19.7 \mathrm{ppm})$ as the internal standards, respectively.

${ }^{19} \mathrm{~F}$ NMR spectra were measured with a JEOL JNMECP600NK spectrometer in THF- $d_{8}$ using benzotrifluoride $(\delta-64.0 \mathrm{ppm})$ as an internal standard. One-dimensional ${ }^{19} \mathrm{~F}$ NOE NMR of ${ }^{29} \mathrm{Si}$ resonance at $\delta-31.2 \mathrm{ppm}$ was measured with a JEOL JNM-ECP600NK spectrometer in THF- $d_{8}$ using benzotrifluoride $(\delta-64.0 \mathrm{ppm})$ as an internal standard.

AFM experiments were conducted in ambient conditions using a SPA-3800N microscope with a SPA-400 scanner (Seiko Instruments Inc., Japan) equipped with a Si-DF20 cantilever. Polymers were dissolved in toluene (to a concentration of about $1.0 \mu \mathrm{g} / \mathrm{mL}$ ). The solution was then deposited on mica. All images were obtained by the dynamic force mode in air, and the drive frequencies were typically set at 110 $150 \mathrm{kHz}$. All images were collected with the maximum available number of pixels (512). TEM images were obtained with a JEOL JEM-3100FEF electron microscope at $300 \mathrm{kV}$. Cryo-HR-TEM observation was carried out at $-140{ }^{\circ} \mathrm{C}$. 
Samples for TEM were prepared by spraying a toluene solution (1.0 wt \%) in water and placing it on a 200-A mesh copper TEM grid. Other TEM samples were prepared by casting toluene solution $(1.0 \mathrm{wt} \%)$ on a carbon film coated microgrid. No staining was necessary for any images. The polymer width was measured for about 230 randomly selected molecules.

\section{Synthesis of Di- $n$-hexylmethyl-3,3,3-trifluoropropylsilane}

The synthetic procedure of di- $n$-hexylmethyl-3,3,3-trifluoropropylsilane ( $\mathrm{Si7})$ is described as follows. 1-Bromohexane (TCI, $18.2 \mathrm{~g}, 110 \mathrm{mmol}$ ) was reacted with magnesium (Wako, $2.89 \mathrm{~g}, 119 \mathrm{mmol}$ ) in dry tetrahydrofuran (Wako, $80.0 \mathrm{~mL}$ ) for $2 \mathrm{~h}$ at $80^{\circ} \mathrm{C}$. The Grignard reagent was added to methyl-3,3,3trifluoropropyldichlorosilane (M2) (Shin-Etsu, 9.66 g, 45.8 $\mathrm{mmol}$ ) in dry tetrahydrofuran (Wako, $80.0 \mathrm{~mL}$ ) at $80^{\circ} \mathrm{C}$. After $21 \mathrm{~h}$, the salts were removed by filtration from the reaction mixture. The crude product was purified by vacuum distillation to give the desired monomer as a colorless liquid, with a yield of $21 \%(3.00 \mathrm{~g})$. The boiling point was determined to be $112-$ $113{ }^{\circ} \mathrm{C}$ (5.0 Torr); ${ }^{1} \mathrm{H}$ NMR (399.00 MHz, $\left.\mathrm{CDCl}_{3}, \mathrm{ppm}\right)-0.02$ (s, Si-CH $\boldsymbol{H}_{3}, 0.51$ (m, Si- $\left.\mathrm{CH}_{2}-\mathrm{CH}_{2}-\right), 0.71$ (m, Si- $\mathrm{CH}_{2}-\mathrm{CH}_{2}-$ $\mathrm{CF}_{3}$ ), 0.88 (t, - $\left.\mathrm{CH}-\mathrm{CH}_{3}\right), 1.29$ (m, -Si- $\left.\mathrm{CH}_{2}-\mathrm{CH}_{2}-\right), 1.99$ (m, Si$\left.\mathrm{CH}_{2}-\mathrm{CH}_{2}-\mathrm{CF}_{3}\right) ;{ }^{13} \mathrm{C} \mathrm{NMR}\left(100.00 \mathrm{MHz}, \mathrm{CDCl}_{3}, \mathrm{ppm}\right)-5.53$ $\left(\mathrm{Si}-\mathrm{CH}_{3}\right), 5.51\left(\mathrm{Si}-\mathrm{CH}_{2}-\mathrm{CH}_{2}-\mathrm{CF}_{3}\right), 13.4\left(\mathrm{Si}-\mathrm{CH}_{2}-\mathrm{CH}_{2}-\right), 14.1$ $\left(-\mathrm{CH}_{2}-\mathrm{CH}_{3}\right), 22.6\left(-\mathrm{CH}_{2}-\mathrm{CH}_{3}\right), 23.7\left(\mathrm{Si}_{-} \mathrm{CH}_{2}-\mathrm{CH}_{2}-\right), 29.0(\mathrm{Si}-$ $\left.\mathrm{CH}_{2}-\mathrm{CH}_{2}-\mathrm{CF}_{3}\right), 31.6\left(-\mathrm{CH}_{2}-\mathrm{CH}_{2}-\mathrm{CH}_{3}\right), 33.4\left(\mathrm{Si}-\mathrm{CH}_{2}-\mathrm{CH}_{2}-\right.$ $\left.\mathrm{CH}_{2}-\right), 126\left(\mathrm{Si}-\mathrm{CH}_{2}-\mathrm{CH}_{2}-\mathrm{CF}_{3}\right) ;{ }^{29} \mathrm{Si} \mathrm{NMR}\left(79.00 \mathrm{MHz}, \mathrm{CDCl}_{3}\right.$, ppm) 3.68; ${ }^{19} \mathrm{~F}$ NMR (564.69 $\left.\mathrm{MHz}, \mathrm{CDCl}_{3}, \mathrm{ppm}\right)-70.0$.

\section{Monomer Preparation}

The dialkylsilane monomer, $i$-butyl- $n$-decyldichlorosilane (M1), was synthesized as follows. First, 1-bromodecane (TCI, $25.2 \mathrm{~g}, 114 \mathrm{mmol}$ ) was reacted with magnesium (Wako, $3.28 \mathrm{~g}$, $135 \mathrm{mmol}$ ) in dry tetrahydrofuran (Wako, $80.0 \mathrm{~mL}$ ) for $1 \mathrm{~h}$ at $80^{\circ} \mathrm{C}$. The Grignard reagent was added to $i$-butyltrichlorosilane (Shin-Etsu, $20.0 \mathrm{~g}, 104 \mathrm{mmol}$ ) in a mixture of dry tetrahydrofuran (Wako, $80.0 \mathrm{~mL}$ ) and diethylether (Wako, $300 \mathrm{~mL}$ ) at $35^{\circ} \mathrm{C}$. After $1 \mathrm{~h}$, the salts were removed by filtration from the reaction mixture. The crude product was purified by vacuum distillation to yield the desired monomer as a colorless liquid, with $54.0 \%$ yield $(17.0 \mathrm{~g})$. The boiling point was determined to be $117-120^{\circ} \mathrm{C}$ (8.0 Torr); ${ }^{1} \mathrm{H}$ NMR $\left(399.00 \mathrm{MHz}, \mathrm{CDCl}_{3}\right.$, ppm) 0.88 (t, - $\left.\mathrm{CH}_{2}-\mathrm{CH}_{3}\right), 1.02$ (d, - $\left.\mathrm{CH}-\mathrm{CH}_{3}\right), 1.09$ (m, -Si$\left.\mathrm{CH}_{2}-\right), 1.26\left(\mathrm{~m},-\mathrm{CH}_{2}-\right), 1.50\left(\mathrm{~m},-\mathrm{Si}-\mathrm{CH}_{2}-\mathrm{CH}_{2}-\mathrm{CH}_{2}-\right), 2.00$ $\left(\mathrm{m},-\mathrm{CH}-\mathrm{CH}_{3}\right) ;{ }^{13} \mathrm{C} \mathrm{NMR}\left(100.00 \mathrm{MHz}, \mathrm{CDCl}_{3}, \mathrm{ppm}\right) 14.1$, 21.3, 22.4, 22.7, 24.2, 25.6, 29.1, 29.3, 29.4, 29.6, 30.4, 31.9, 32.5; ${ }^{29} \mathrm{Si} \mathrm{NMR}\left(79.00 \mathrm{MHz}, \mathrm{CDCl}_{3}, \mathrm{ppm}\right) 32.6$.

Methyl-3,3,3-trifluoropropyldichlorosilane (M2) and methyl-n-propyldichlorosilane (M3) were purchased from ShinEtsu and purified by vacuum distillation prior to polymerization.

\section{Synthesis of Polymers}

For PSi1-3, the composition fractions were estimated by ${ }^{1} \mathrm{H}$ NMR measurements. Global conformation of PSis was estimated by the semi-empirical formula $\varepsilon^{\text {abs }}=1130 \times 10^{2.9 \alpha}$, which was derived from the relationship between main chain absorption intensity per silicon repeat unit (Si repeat unit) ${ }^{-1}$ $\mathrm{dm}^{3} \mathrm{~cm}^{-1} \varepsilon^{\mathrm{abs}}$ and the viscosity index $\alpha{ }^{16}$

Poly $\left[(i \text {-butyl-n-decylsilane) })_{\mathrm{x}}\right.$-co-(methyl-3,3,3-trifluoropropylsilane $)_{1-\mathbf{x}}$ ] (PSi1a). A freshly distilled mixture of M1 (2.70 g, $9.10 \mathrm{mmol})$ and M2 (1.90 g, $9.10 \mathrm{mmol})$ was added dropwise

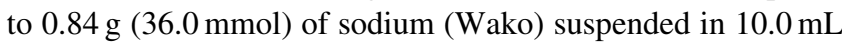
of refluxing toluene (Wako), and the mixture was vigorously stirred under atmospheric nitrogen at $120^{\circ} \mathrm{C}$. After $2 \mathrm{~h}$, $90.0 \mathrm{~mL}$ of dry toluene (Wako) was further added to reduce the solution viscosity, and stirring was continued for an additional $1 \mathrm{~h}$ at $100^{\circ} \mathrm{C}$. The hot reaction mixture was immediately passed through a $2 \mu \mathrm{m}$ pore size PTFE filter (Sumitomo Electric) under nitrogen gas pressure. The precipitating solvents, 2-propanol, ethanol, and methanol, were carefully added to the clear filtrate. Several portions of white precipitate were collected by centrifugation and dried under vacuum at $80{ }^{\circ} \mathrm{C} .{ }^{1} \mathrm{H} \mathrm{NMR}\left(399.00 \mathrm{MHz}, \mathrm{CDCl}_{3}, \mathrm{ppm}\right) 0.37$ (br, -Si- $\mathrm{CH}_{3}$ ), 0.87 (t, - $\mathrm{CH}_{2}-\mathrm{CH}_{3}$ ), 0.98 (br, -Si- $\mathrm{CH}_{2-}$, - $\mathrm{CH}-$ $\mathrm{CH}_{3}$ ), 1.10 (br, -Si-CH$-\mathrm{CH}_{2}-\mathrm{CF}_{3}$ ), 1.26 (br, $-\mathrm{CH}_{2}-$ ), 1.73 (br, $\left.-\mathrm{CH}-\mathrm{CH}_{3}\right), 2.06$ (br, $\left.-\mathrm{Si}-\mathrm{CH}_{2}-\mathrm{CH}_{2}-\mathrm{CF}_{3}\right) ;{ }^{29} \mathrm{Si} \mathrm{NMR}(79.00$ $\left.\mathrm{MHz}, \mathrm{CDCl}_{3}, \mathrm{ppm}\right)-23.1\left(\mathrm{Si}-\mathrm{CH}_{2}-\mathrm{CH}\left(\mathrm{CH}_{3}\right)-\mathrm{CH}_{3}\right),-31.7$ $\left(\mathrm{Si}-\mathrm{CH}_{2}-\mathrm{CH}_{2}-\mathrm{CF}_{3}\right) ;{ }^{19} \mathrm{~F} \mathrm{NMR} \quad\left(564.69 \mathrm{MHz}, \mathrm{CDCl}_{3}, \mathrm{ppm}\right)$ -69.9; FT-IR $\left(\mathrm{cm}^{-1}\right) 2955\left(v_{\mathrm{as}}\left(\mathrm{CH}_{3}\right)\right), 2925\left(v_{\mathrm{as}}\left(\mathrm{CH}_{2}\right)\right), 2872$ $\left(v_{\mathrm{s}}\left(\mathrm{CH}_{3}\right)\right), 2855\left(v_{\mathrm{s}}\left(\mathrm{CH}_{2}\right)\right), 1262\left(\delta_{\mathrm{s}}\left(\mathrm{SiCH}_{3}\right)\right), 1214\left(v_{\mathrm{as}}(\mathrm{CF})\right)$, $1198(v(\mathrm{CC})), 1130\left(v_{\mathrm{s}}(\mathrm{CF})\right)$.

Poly[(i-butyl-n-decylsilane $)_{\mathrm{x}}$-co-(methyl-3,3,3-trifluoropropylsilane $)_{1-\mathbf{x}}$ ] (PSi1b). A freshly distilled monomer mixture of M1 (3.57 g, $12.0 \mathrm{mmol})$ and M2 (0.84 g, $4.00 \mathrm{mmol})$ was added dropwise to $1.47 \mathrm{~g}(64.0 \mathrm{mmol})$ of sodium (Wako) suspended in $10.0 \mathrm{~mL}$ of refluxing toluene (Wako), and the mixture was vigorously stirred under atmospheric nitrogen at $120^{\circ} \mathrm{C}$. After $2 \mathrm{~h}, 90.0 \mathrm{~mL}$ of dry toluene (Wako) was added to reduce the solution viscosity, and stirring was continued for an additional $1 \mathrm{~h}$ at $100^{\circ} \mathrm{C}$. The hot reaction mixture was passed through a $2 \mu \mathrm{m}$ PTFE filter under nitrogen gas pressure. The precipitating solvents, 2-propanol, ethanol, and methanol, were added carefully to the clear filtrate. Several portions of white precipitate were collected by centrifugation and dried under vacuum at $80{ }^{\circ} \mathrm{C} .{ }^{1} \mathrm{H} \mathrm{NMR}\left(399.00 \mathrm{MHz}, \mathrm{CDCl}_{3}, \mathrm{ppm}\right) 0.37$ (br, -Si- $\mathrm{CH}_{3}$ ), 0.87 (t, - $\mathrm{CH}_{2}-\mathrm{CH}_{3}$ ), 0.99 (br, -Si- $\mathrm{CH}_{2-}^{-},-\mathrm{CH}-$ $\mathrm{CH}_{3}$ ), 1.10 (br, $-\mathrm{Si}-\mathrm{CH}_{2}-\mathrm{CH}_{2}-\mathrm{CF}_{3}$ ), 1.26 (br, $\left.-\mathrm{CH}_{2}-\right), 1.73$ (br, $\left.-\mathrm{CH}-\mathrm{CH}_{3}\right), 2.07$ (br, $\left.-\mathrm{Si}-\mathrm{CH}_{2}-\mathrm{CH}_{2}-\mathrm{CF}_{3}\right) ;{ }^{29} \mathrm{Si} \mathrm{NMR}(79.00$ $\left.\mathrm{MHz}, \mathrm{CDCl}_{3}, \mathrm{ppm}\right)-23.2\left(\mathrm{Si}-\mathrm{CH}_{2}-\mathrm{CH}\left(\mathrm{CH}_{3}\right)-\mathrm{CH}_{3}\right),-31.6$ ( $\mathrm{Si}-\mathrm{CH}_{2}-\mathrm{CH}_{2}-\mathrm{CF}_{3}$ ).

Poly $\left[(i \text {-butyl-n-decylsilane) })_{\mathrm{x}}\right.$-co-(methyl-3,3,3-trifluoropropylsilane $)_{1-\mathbf{x}}$ ] (PSi1c). A freshly distilled monomer mixture of M1 (2.38 g, $8.00 \mathrm{mmol})$ and M2 (5.06 g, $24.0 \mathrm{mmol})$ was added dropwise to $2.94 \mathrm{~g}$ (128 mmol) of sodium (Wako) suspended in $16.0 \mathrm{~mL}$ of refluxing $n$-nonane (Aldrich), and the mixture was vigorously stirred under atmospheric nitrogen at $125^{\circ} \mathrm{C}$. After $2 \mathrm{~h}, 90.0 \mathrm{~mL}$ of dry THF (Wako) was added to reduce the solution viscosity, and stirring continued for an additional $30 \mathrm{~min}$. The reaction mixture was passed through a $2 \mu \mathrm{m}$ PTFE filter under nitrogen gas pressure. The precipitating solvents, 
2-propanol, ethanol, and methanol, were added carefully to the clear filtrate. Several portions of white precipitate were collected by centrifugation and dried under vacuum at $80^{\circ} \mathrm{C}$. ${ }^{1} \mathrm{H}$ NMR (399.00 MHz, $\left.\mathrm{CDCl}_{3}, \mathrm{ppm}\right) 0.36$ (br, $\left.-\mathrm{Si}-\mathrm{CH}_{3}\right), 0.88$ (t, - $\mathrm{CH}_{2}-\mathrm{CH}_{3}$ ), 0.98 (br, -Si- $\mathrm{CH}_{2-},-\mathrm{CH}-\mathrm{CH}_{3}$ ), 1.05 (br, -Si$\mathrm{CH}_{2}-\mathrm{CH}_{2}-\mathrm{CF}_{3}$ ), 1.25 (br, $-\mathrm{CH}_{2}-$ ), undetectable (br, - $\mathrm{CH}-\mathrm{CH}_{3}$ ), 2.05 (br, $\left.-\mathrm{Si}-\mathrm{CH}_{2}-\mathrm{CH}_{2}-\mathrm{CF}_{3}\right) ;{ }^{29} \mathrm{Si} \mathrm{NMR}\left(79.00 \mathrm{MHz}, \mathrm{CDCl}_{3}\right.$, ppm) undetectable $\left(\mathrm{Si}-\mathrm{CH}_{2}-\mathrm{CH}\left(\mathrm{CH}_{3}\right)-\mathrm{CH}_{3}\right),-31.9\left(\mathrm{Si}-\mathrm{CH}_{2}-\right.$ $\left.\mathrm{CH}_{2}-\mathrm{CF}_{3}\right)$.

Poly $\left[(i \text {-butyl- } n \text {-decylsilane })_{\mathrm{x}}\right.$ - - 0 - $\left.(\text { methyl- } n \text {-propylsilane })_{1-\mathrm{x}}\right]$ (PSi2). A mixture of $0.92 \mathrm{~g}(40.4 \mathrm{mmol})$ of sodium (Wako) and $0.05 \mathrm{~g}(0.20 \mathrm{mmol})$ of 18 -crown-6 (Wako) in $10.0 \mathrm{~mL}$ of dry toluene (Wako) was added dropwise to a monomer mixture of M1 (3.02 g, $10.1 \mathrm{mmol})$ and M3 (1.58 g, $10.1 \mathrm{mmol})$ in atmospheric nitrogen at $120^{\circ} \mathrm{C}$. After $1 \mathrm{~h}, 100 \mathrm{~mL}$ of dry toluene (Wako) was added to reduce the solution viscosity, and stirring was continued for an additional $1 \mathrm{~h}$ at $100^{\circ} \mathrm{C}$. The hot reaction mixture was passed through a $2 \mu \mathrm{m}$ PTFE filter under nitrogen gas pressure. The precipitating solvents, 2-propanol, ethanol, and methanol, were added carefully to the clear filtrate. Several portions of white precipitate were collected by centrifugation and dried under vacuum at $80{ }^{\circ} \mathrm{C}$. ${ }^{1} \mathrm{H} \mathrm{NMR}$ (399.00 MHz, $\mathrm{CDCl}_{3}, \mathrm{ppm}$ ) 0.25 (br, -Si-CH ), 0.85 (br, -Si$\mathrm{CH}_{2}-\mathrm{CH}_{2}-\mathrm{CH}_{3}$ ), 0.87 (t, $\left.-\mathrm{CH}_{2}-\mathrm{CH}_{3}\right), 0.98$ (br, $-\mathrm{Si}-\mathrm{CH}_{2}-\mathrm{CH}_{2}-$ $\mathrm{CH}_{3},-\mathrm{Si}-\mathrm{CH}_{2-}^{-},-\mathrm{CH}-\mathrm{CH}_{3}$ ), 1.26 (br, $-\mathrm{CH}_{2-}$ ), 1.37 (br, -Si$\mathrm{CH}_{2}-\mathrm{CH}_{2}-\mathrm{CH}_{3}$ ), 1.78 (br, $\left.-\mathrm{CH}-\mathrm{CH}_{3}\right) ;{ }^{29} \mathrm{Si} \mathrm{NMR}(79.00 \mathrm{MHz}$, $\left.\mathrm{CDCl}_{3}, \mathrm{ppm}\right)-23.0\left(\mathrm{Si}-\mathrm{CH}_{2}-\mathrm{CH}\left(\mathrm{CH}_{3}\right)-\mathrm{CH}_{3}\right),-32.5\left(\mathrm{Si}-\mathrm{CH}_{2}-\right.$ $\left.\mathrm{CH}_{2}-\mathrm{CH}_{3}\right)$.

Poly[(methyl-n-propylsilane) $)_{\mathrm{x}}$-co-(methyl-3,3,3-trifluoropropylsilane $)_{1-\mathrm{x}}$ ] (PSi3). A freshly distilled monomer mixture of M2 (4.83 g, $22.9 \mathrm{mmol})$ and $\mathrm{M3}(3.60 \mathrm{~g}, 22.9 \mathrm{mmol})$ was added dropwise to $2.10 \mathrm{~g}(91.6 \mathrm{mmol})$ of sodium (Wako) suspended in $16.0 \mathrm{~mL}$ of refluxing toluene (Wako), and the mixture was vigorously stirred under atmospheric nitrogen at $120^{\circ} \mathrm{C}$. After $2 \mathrm{~h}, 120 \mathrm{~mL}$ of dry toluene (Wako) was added to reduce the solution viscosity, and stirring was continued for an additional $1 \mathrm{~h}$ at $100^{\circ} \mathrm{C}$. The hot reaction mixture was passed through a $2 \mu \mathrm{m}$ PTFE filter under nitrogen gas pressure. The precipitating solvent, methanol, was added carefully to the clear filtrate. Several portions of white precipitate were collected by centrifugation and dried under vacuum at $80{ }^{\circ} \mathrm{C}$. ${ }^{1} \mathrm{H} \mathrm{NMR}$ (399.00 MHz, $\mathrm{CDCl}_{3}, \mathrm{ppm}$ ) 0.30 (br, -Si-CH ), 0.83 (br, -Si$\mathrm{CH}_{2}-\mathrm{CH}_{2}-\mathrm{CH}_{3}$ ), 1.01 (br, $-\mathrm{Si}-\mathrm{CH}_{2}-\mathrm{CH}_{2}-\mathrm{CH}_{3},-\mathrm{Si}-\mathrm{CH}_{2}-\mathrm{CH}_{2}-$ $\mathrm{CF}_{3}$ ), 1.35 (br, $-\mathrm{Si}-\mathrm{CH}_{2}-\mathrm{CH}_{2}-\mathrm{CH}_{3}$ ), 2.03 (br, $-\mathrm{Si}-\mathrm{CH}_{2}-\mathrm{CH}_{2}-$ $\left.\mathrm{CF}_{3}\right) ;{ }^{29} \mathrm{Si} \mathrm{NMR}\left(79.00 \mathrm{MHz}, \mathrm{THF}-d_{8}, \mathrm{ppm}\right)-31.9\left(\mathrm{Si}-\mathrm{CH}_{2}-\right.$ $\left.\mathrm{CH}_{2}-\mathrm{CF}_{3}\right),-32.5\left(\mathrm{Si}-\mathrm{CH}_{2}-\mathrm{CH}_{2}-\mathrm{CH}_{3}\right)$; FT-IR (cm $\left.{ }^{-1}\right) 2957$ $\left(v_{\text {as }}\left(\mathrm{CH}_{3}\right)\right), 2930\left(v_{\mathrm{as}}\left(\mathrm{CH}_{2}\right)\right), 2900\left(v_{\mathrm{s}}\left(\mathrm{CH}_{3}\right)\right), 2872\left(v_{\mathrm{s}}\left(\mathrm{CH}_{2}\right)\right)$, $1264\left(\delta_{\mathrm{s}}\left(\mathrm{SiCH}_{3}\right)\right), 1213\left(v_{\mathrm{as}}(\mathrm{CF})\right), 1198(v(\mathrm{CC})), 1126\left(v_{\mathrm{s}}(\mathrm{CF})\right)$. Poly(i-butyl-n-decylsilane) (PSi4). A mixture of $0.92 \mathrm{~g} \mathrm{(40.4}$ mmol) of sodium (Wako) and $0.05 \mathrm{~g}(0.20 \mathrm{mmol})$ of 18 crown-6 (Wako) in $12.0 \mathrm{~mL}$ of dry toluene (Wako) was added dropwise to $3.00 \mathrm{~g}(10.0 \mathrm{mmol})$ of $\mathrm{M} 1$ in atmospheric nitrogen at $120^{\circ} \mathrm{C}$. After $2 \mathrm{~h}, 100 \mathrm{~mL}$ of dry toluene (Wako) was added to reduce the solution viscosity, and stirring was continued for an additional $1 \mathrm{~h}$ at $100{ }^{\circ} \mathrm{C}$. The hot reaction mixture was passed through a $2 \mu \mathrm{m}$ PTFE filter under nitrogen gas pressure.
The precipitating solvents, 2-propanol, ethanol, and methanol, were added carefully to the clear filtrate. Several portions of white precipitate were collected by centrifugation and dried under vacuum at $80{ }^{\circ} \mathrm{C} .{ }^{1} \mathrm{H} \mathrm{NMR}\left(399.00 \mathrm{MHz}, \mathrm{CDCl}_{3}, \mathrm{ppm}\right)$ 0.88 (t, - $\mathrm{CH}_{2}-\mathrm{CH}_{3}$ ), 0.97 (br, -Si- $\mathrm{CH}_{2}-,-\mathrm{CH}-\mathrm{CH}_{3}$ ), 1.26 (br, $\left.-\mathrm{CH}_{2}-\right), 1.70$ (br, $\left.-\mathrm{CH}-\mathrm{CH}_{3}\right) ;{ }^{29} \mathrm{Si} \mathrm{NMR}\left(79.00 \mathrm{MHz}, \mathrm{CDCl}_{3}\right.$, ppm) -23.3 .

Poly(methyl-3,3,3-trifluoropropylsilane) (PSi5). A freshly distilled monomer of M2 $(4.28 \mathrm{~g}, 20.0 \mathrm{mmol})$ was added dropwise to $1.85 \mathrm{~g}(80.0 \mathrm{mmol})$ of sodium (Wako) suspended in $10.0 \mathrm{~mL}$ of refluxing $n$-nonane (Aldrich), and the mixture was vigorously stirred under nitrogen atmosphere at $120^{\circ} \mathrm{C}$. After $5 \mathrm{~h}$, the reaction mixture was cooled to room temperature, $90.0 \mathrm{~mL}$ of dry tetrahydrofuran (Wako) was added to reduce the solution viscosity, and stirring was continued for an additional $30 \mathrm{~min}$. The reaction mixture was passed through a $2 \mu \mathrm{m}$ PTFE filter under nitrogen gas pressure. Methanol was carefully added to the clear filtrate as a precipitating solvent. Several portions of white precipitate were collected by centrifugation and dried under vacuum at $80{ }^{\circ} \mathrm{C}$. ${ }^{1} \mathrm{H} \mathrm{NMR}$ (399.00 MHz, $\left.\mathrm{CDCl}_{3}, \mathrm{ppm}\right) 0.30$ (br, -Si-CH $\boldsymbol{H}_{3}$, 1.01 (br, -Si$\mathrm{CH}_{2}-\mathrm{CH}_{2}-\mathrm{CF}_{3}$ ), 2.04 (br, $\left.-\mathrm{Si}-\mathrm{CH}_{2}-\mathrm{CH}_{2}-\mathrm{CF}_{3}\right) ;{ }^{29} \mathrm{Si} \mathrm{NMR}$ (79.00 MHz, THF- $\left.d_{8}, \mathrm{ppm}\right)-31.8 ;{ }^{19} \mathrm{~F}$ NMR $(564.69 \mathrm{MHz}$, THF- $\left.d_{8}, \mathrm{ppm}\right)-70.1$; FT-IR $\left(\mathrm{cm}^{-1}\right) 1265\left(\delta_{\mathrm{s}}\left(\mathrm{SiCH}_{3}\right)\right), 1210$ $\left(v_{\text {as }}(\mathrm{CF})\right), 1198(v(\mathrm{CC})), 1125\left(v_{\mathrm{s}}(\mathrm{CF})\right)$.

\section{CONCLUSIONS}

The present paper demonstrated novel organogelation of semiflexible PSi bearing trifluoroalkyl groups through the proper combination of weak $\mathrm{Si} / \mathrm{FC}$ intrachain/interchain and van der Waals intrachain/interchain interactions in nonpolar organic solvents. The existence of $\mathrm{Si} / \mathrm{FC}$ interchain interactions was first characterized by IR using a model silane molecule. Hierarchical structures at the meso- and nanoscopic levels were characterized by AFM, cryo-HR-TEM, IR, and ${ }^{19} \mathrm{~F}\left\{{ }^{29} \mathrm{Si}\right\}$-NOE NMR experiments. The present results may represent the beginning of a new type of molecular design for self-assembled nano-architectures, including polymer gelators.

Acknowledgment. The authors thank Prof. Tsuyoshi Kawai, Prof. Jun-ichi Kikuchi, Prof. Masao Tanihara, Prof. Kotohiro Nomura, and Dr. Hisanari Onouchi for fruitful discussions. We acknowledge support by the Ministry of Education, Science, Sports, and Culture of Japan, and a Grant-in-Aid for Scientific Research (17750110 and 16655046). We also acknowledge partial funding from Scientific Research of Priority Areas (446). This paper is dedicated to the memory of the late Prof. Junzo Sunamoto, who encouraged us to investigate the polysilane organogel via $\mathrm{Si} / \mathrm{FC}$ intrachain/interchain interactions.

Received: October 16, 2007 Accepted: December 25, 2007 Published: February 19, 2008 


\section{REFERENCES}

1. Y. Osada and J.-P. Gong, Adv. Mater., 10, 827 (1998).

2. T. Ono, T. Sugimoto, S. Shinkai, and K. Sada, Nat. Mater., 6, 429 (2007).

3. M. Annaka, T. Tanaka, and Y. Osada, Macromolecules, 25, 4826 (1992).

4. S. Morita, T. Kawai, and K. Yoshino, J. Appl. Phys., 69, 4445 (1991).

5. G. R. Desiraju and T. Steiner, "The Weak Hydrogen Bond-In Structural Chemistry and Biology," Oxford Univ Press, New York, 1999.

6. M. Nishio, M. Hirota, and Y. Umezawa, "The $\mathrm{CH} / \pi$ InteractionEvidence, Nature, and Consequences," Wiley-VCH, New York, 1998.

7. H. Matsuura, H. Yoshida, M. Hieda, S. Yamanaka, T. Harada, K. Shin-ya, and K. Ohno, J. Am. Chem. Soc., 125, 13910 (2003).

8. J. L. Alonso, S. Antolínez, S. Blanco, A. Lesarri, J. C. López, and W. Caminati, J. Am. Chem. Soc., 126, 3244 (2004).

9. P. Hobza and Z. Havlas, Chem. Rev., 100, 4253 (2000).

10. A. Y. Li, J. Chem. Phys., 126, 154102 (2007).

11. T. J. Lenk, R. L. Siemens, V. M. Hallmark, R. D. Miller, and J. F. Rabolt, Macromolecules, 24, 1215 (1991).

12. A. Saxena, R. Rai, S.-Y. Kim, M. Fujiki, M. Naito, K. Okoshi, and
G. Kwak, J. Polym. Sci., Part A: Polym. Chem., 44, 5060 (2006).

13. A. Saxena, M. Fujiki, M. Naito, K. Okoshi, and G. Kwak, Macromolecules, 37, 5873 (2004).

14. S.-Y. Kim, A. Saxena, G. Kwak, M. Fujiki, and Y. Kawakami, Chem. Commun., 538 (2004).

15. N. Okamoto, F. Mukaida, H. Gu, Y. Nakamura, T. Sato, A. Teramoto, M. M. Green, C. Andreola, N. C. Peterson, and S. Lifson, Macromolecules, 29, 2878 (1996).

16. M. Fujiki, J. Am. Chem. Soc., 118, 7424 (1996).

17. A. Weissberger, "Organic Solvents," 4th ed., Wiley, New York, (1986).

18. T. Dürrschmidt and H. Hoffmann, Colloid Polym. Sci., 279, 1005 (2001) and references therein.

19. T. Kunitake and N. Higashi, J. Am. Chem. Soc., 107, 692 (1985).

20. R. M. Overney, E. Meyer, J. Frommer, D. Brodbeck, R. Lüthi, L. Howald, H.-J. Güntherodt, M. Fujihira, H. Takano, and Y. Gotoh, Nature, 359, 133 (1992).

21. N. Yamada, T. Imai, and E. Koyama, Langmuir, 17, 961 (2001).

22. M. Suzuki, Y. Nakajima, M. Yumoto, M. Kimura, H. Shirai, and K. Hanabusa, Langmuir, 19, 8622 (2003).

23. M. Naito, N. Saeki, M. Fujiki, and A. Ohira, Macromolecules, 40, 648 (2007).

24. M. Fujino, T. Hisaki, and N. Matsumoto, J. Polym. Sci., Part A: Polym. Chem., 33, 2279 (1995). 